\title{
Devitrification of mechanically alloyed Fe-Nb system: Mössbauer study of the intermetallic phases
}

A.F. Manchón-Gordón ${ }^{1}$, P. Svec ${ }^{2}$, J.J. Ipus ${ }^{1}$, M. Kowalczyk ${ }^{3}$, J.S. Blázquez ${ }^{* 1}$, C.F. Conde $^{1}$, A. Conde ${ }^{1}$, P. Svec Sr. ${ }^{2}$, T. Kulik ${ }^{3}$

${ }^{1}$ Dpto. Física de la Materia Condensada, ICMSE-CSIC, Universidad de Sevilla, P.O. Box 1065, 41080 Sevilla, Spain

${ }^{2}$ Institute of Physics. Slovak Academy of Sciences. Dúbravská cesta 9, 84511 Bratislava 45, Slovak Republic.

${ }^{3}$ Faculty of Materials Science and Engineering, Warsaw University of Technology, 141 Wołoska st., 02-507 Warsaw, Poland

"The corresponding authore-mail: jsebas@us.es

ABSTRACT: Intermetallic phases in the Fe- $\mathrm{Nb}$ system have been obtained as products of the devitrification of a homogeneous amorphous $\mathrm{Fe}_{70} \mathrm{Nb}_{30}$ alloy prepared by mechanical alloying. Besides $\mathrm{Fe}_{2} \mathrm{Nb}$ Laves and $\mathrm{Fe}_{7} \mathrm{Nb}_{6}$ intermetallic phases, $\alpha$-Fe phase has been detected by X-ray diffraction (XRD). Hyperfine parameters for both $\mathrm{Fe}_{2} \mathrm{Nb}$ and $\mathrm{Fe}_{7} \mathrm{Nb}_{6}$ intermetallics have been obtained from Mössbauer spectroscopy in correlation with phase identification from XRD results. Thermomagnetic measurements show changes in the Curie temperatures of the amorphous and $\mathrm{Fe}_{2} \mathrm{Nb}$ phases during the crystallization, due to compositional variations related to the developing of the $\alpha$-Fe phase. Kinetics of the crystallization process has been analyzed using the classical Johnson-Mehl-Avrami-Kolmogorov kinetic theory in both isothermal and nonisothermal regimes.

KEYWORDS: Fe-Nb intermetallics, amorphous and nanocrystalline alloys, Mössbauer spectroscopy, crystallization kinetics.

\section{INTRODUCTION}


Fe-Nb systems have received a particular interest in the research community essentially due to their wide range of different applications in industry, mainly as special stainless steels $^{1-4}$ and as soft magnets ${ }^{5,6}$. Indeed, the presence of $\mathrm{Nb}$ in the Fe matrix limits the formation of $\alpha$-Fe grains to the nanometric scale, improving the mechanical properties (through solid solution and/or precipitation strengthening ${ }^{1,2}$ ) and the magnetic softness (through averaging out the magnetocrystalline anisotropy ${ }^{7}$ ).

In spite of the interest on this system, there are some discrepancies in the literature on the complete $\mathrm{Fe}-\mathrm{Nb}$ phase diagram, particularly on the melt and the homogeneity ranges of the intermetallic phases ${ }^{8-10}$. In fact, while a previous $\mathrm{Fe}-\mathrm{Nb}$ phase diagram ${ }^{11}$ showed four intermetallics (including a possible high temperature phase at 90 at.\% $\mathrm{Nb}$ ), recent results indicate the existence of only two intermetallic phases, the hexagonal $\mathrm{Fe}_{2} \mathrm{Nb}$ and the trigonal $\mathrm{Fe}_{7} \mathrm{Nb}_{6}$ phases ${ }^{8}$.

Many techniques have been used to produce $\mathrm{Fe}-\mathrm{Nb}$ alloys. However, the poor solubility of niobium in the iron lattice ( $\mathrm{Fe}-\mathrm{Nb}$ mixing enthalpy $-16 \mathrm{~kJ} / \mathrm{mol}^{12}$ ) limits the production of homogenous $\mathrm{Fe}-\mathrm{Nb}$ systems by melting methods to concentrations higher than 33 at. $\% \mathrm{Nb}^{13}$, due to the large difference between the melting temperatures of these elements (1811 and $2750 \mathrm{~K}$ for $\mathrm{Fe}$ and $\mathrm{Nb}$, respectively ${ }^{8}$ ). Therefore, the production of samples out of the eutectic compositions requires other ways, such as mechanical alloying. This method often produces non-equilibrium solid solutions and amorphous phases $^{14-16}$. Consequently, additional thermal treatments are necessary to develop stable crystalline phases. In this sense, the combination of X-ray diffraction (XRD) and Mössbauer spectroscopy (MS) techniques in iron-based systems allows studying in detail the final products of the crystallization process ${ }^{17,18}$. 
Concerning the devitrification process, crystallization kinetics can be characterized by Johnson and $\mathrm{Mehl}^{19}$, Avrami $^{20}$ and Kolmogorov ${ }^{21}$ classical crystallization theory (JMAK theory). Although JMAK theory was developed to be applied to isothermal polymorphic transformations, it has been successfully extended to transformations implying compositional changes ${ }^{22,23}$ and to non-isothermal processes ${ }^{24-29}$. Compared to isothermal experiments, non-isothermal processes have the advantages of an easier operation, lower time cost and higher signal-to-noise ratio ${ }^{28}$.

In this work, an amorphous Fe alloy with 30 at.\% $\mathrm{Nb}$ has been synthesized by means of mechanical alloying in order to obtain a homogeneous sample. Different thermal treatments have been applied in order to develop stable intermetallic $\mathrm{Fe}-\mathrm{Nb}$ phases. The products of the crystallization process have been studied by X-ray diffraction (XRD), Mössbauer spectroscopy (MS) and magnetometry. JMAK theory has been used to describe the crystallization process for non-isothermal and isothermal regimes.

\section{EXPERIMENTAL}

Amorphous alloy with $\mathrm{Fe}_{70} \mathrm{Nb}_{30}$ at.\% composition was prepared by high energy ball milling, starting from high purity elemental powders of iron and niobium (>99.9\%). The milling was carried out for 50 hours at $350 \mathrm{rpm}$ in a planetary ball mill Fritsch Pulverisette Vario 4. Further milling parameters and a detailed microstructural evolution of the sample with milling time can be found elsewhere ${ }^{16}$.

Differential thermal analysis (DTA) was carried out in a Perkin-Elmer DTA7 unit under Ar flow for both isothermal and non-isothermal experiments. Different heating rates $(\beta=5,10,20,40$ and $60 \mathrm{~K} / \mathrm{min})$ were used for non-isothermal treatments up to $1300 \mathrm{~K}$ without evidencing any changes (see supplementary material). In order to follow the 
progress of the transformations, heating at $10 \mathrm{~K} / \mathrm{min}$ up to different temperatures (from 908 to $1300 \mathrm{~K}$ ) was also performed. In the case of isothermal experiments, the amorphous sample was annealed for 5 hours at $954 \mathrm{~K}, 10 \mathrm{~K}$ below the onset temperature obtained for $\beta=10 \mathrm{~K} / \mathrm{min}$ (see Fig. 1a). The corresponding baselines were obtained repeating the same treatment after the complete crystallization of the sample.

XRD patterns were recorded in a Bruker D8 Advance diffractometer $(\mathrm{Cr}-\mathrm{K} \alpha$, $\lambda=2.28970 \AA$ ) in a Bragg-Brentano geometry. The local environment of Fe atoms was analyzed at room temperature by Mössbauer spectrometry in transmission geometry using a ${ }^{57} \mathrm{Co}(\mathrm{Rh})$ source. Values of the hyperfine parameters were obtained by fitting the measured spectra with the NORMOS program ${ }^{30}$ and the isomer shift (IS) was quoted relative to that of an $\alpha-F e$ foil at room temperature.

Magnetization measurements were performed in a vibrating sample magnetometer (standard option of a Quantum Design Physical Properties Measurement System, PPMS) applying a magnetic field of 100 Oe. Curie temperatures $T_{C}$ have been determined by identifying the temperature at which the temperature derivative of magnetization shows a minimum.

\section{RESULTS and DISCUSSION}

\subsection{Characterization of crystallization products}

Figure 1a shows the non-isothermal DTA plot taken at $10 \mathrm{~K} / \mathrm{min}$ for the as-milled amorphous sample. All the features found in the curve vanish in a second heating, which was used as the corresponding baseline. Deviations from baseline at lower temperatures are ascribed to relaxation phenomena. A well-defined exothermic peak can be observed around $950 \mathrm{~K}$, corresponding to the crystallization of the amorphous phase. The measured peak shape in Fig. 1a suggests that at least two transformations are taking 
place. However, no experimental deconvolution could be obtained in the heating rate from 5 to $60 \mathrm{~K} / \mathrm{min}$ (see figure $1 \mathrm{~b}$ ). A second and weaker peak is observed at $\sim 1200 \mathrm{~K}$ in Fig. 1a. The effective value of the activation energy $E_{a}=2.48 \pm 0.07 \mathrm{eV} /$ at, corresponding to the first peak temperature, has been calculated by Kissinger's method $^{31}$ (see inset of Fig. 1b). This value is similar to that reported by El-Eskandarany et al. ${ }^{32}$ for the crystallization of the amorphous $\mathrm{Fe}_{52} \mathrm{Nb}_{48}$ alloy powder obtained by mechanical alloying.

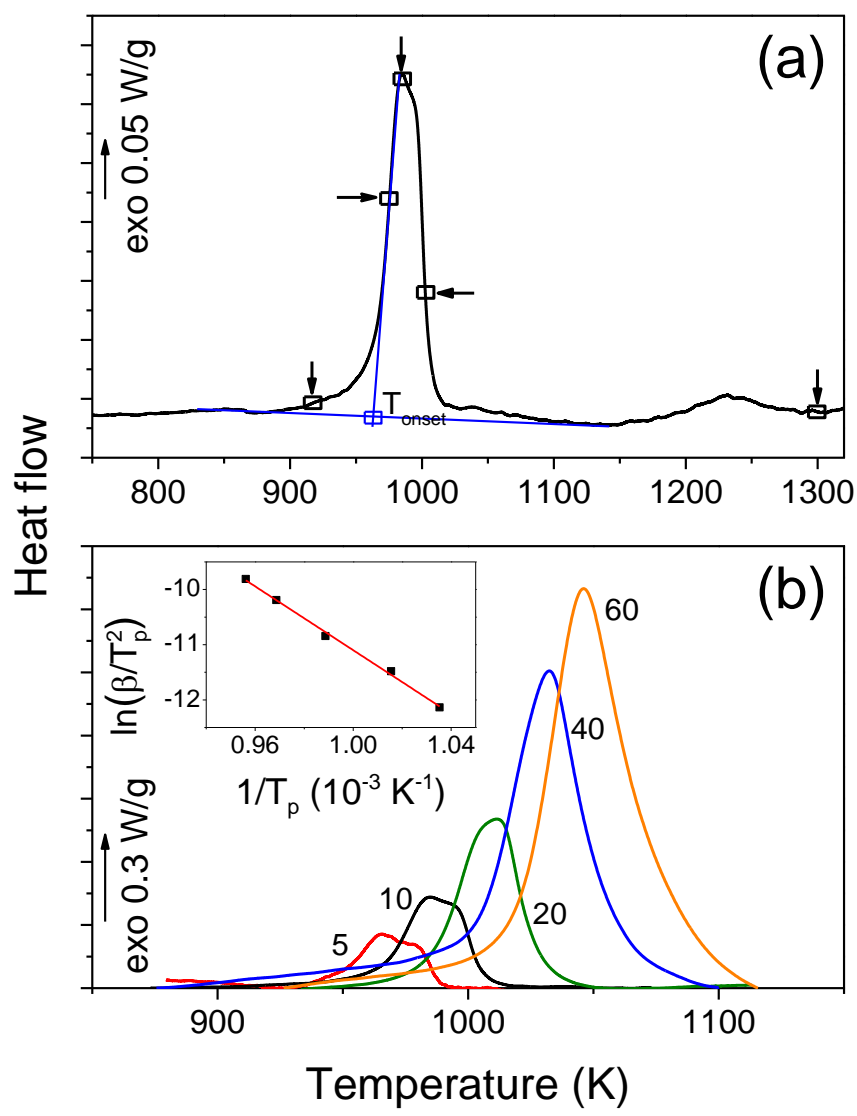

Figure 1. (a) Non-isothermal DTA scan at $10 \mathrm{~K} / \mathrm{min}$ for the as-milled sample. Arrows indicate the temperatures up to which different samples have been heated. The onset temperature is indicated. (b) Non-isothermal DTA scans for as-milled sample at the different indicated heating rates (in $\mathrm{K} / \mathrm{min}$ ) in the region of the first DTA exotherm. The inset shows the Kissinger's plot. 
Figure 2 shows the XRD patterns of as-milled sample and of those samples after heating at $10 \mathrm{~K} / \mathrm{min}$ up to the indicated temperatures to evidence the formation of the different crystalline phases. The as-milled powders only show a broad halo distinctive of an amorphous phase. This broad halo is the only feature observed in the patterns collected for samples heated up to $907 \mathrm{~K}$. Above this temperature, several diffraction peaks appear superimposed to the amorphous halo, corresponding to three phases: hcp $\mathrm{Fe}_{2} \mathrm{Nb}$ (after heating up to $968 \mathrm{~K}$, with space group $\mathrm{P}_{3} / \mathrm{mmc}$ ), bcc-Fe (after heating up to 1003 $\mathrm{K}$, with space group $\mathrm{Im} 3 \mathrm{~m}$ ) and trigonal $\mathrm{Fe}_{7} \mathrm{Nb}_{6}$ (space group $\mathrm{R}-3 \mathrm{~m}$, after heating up to $1273 \mathrm{~K})$.

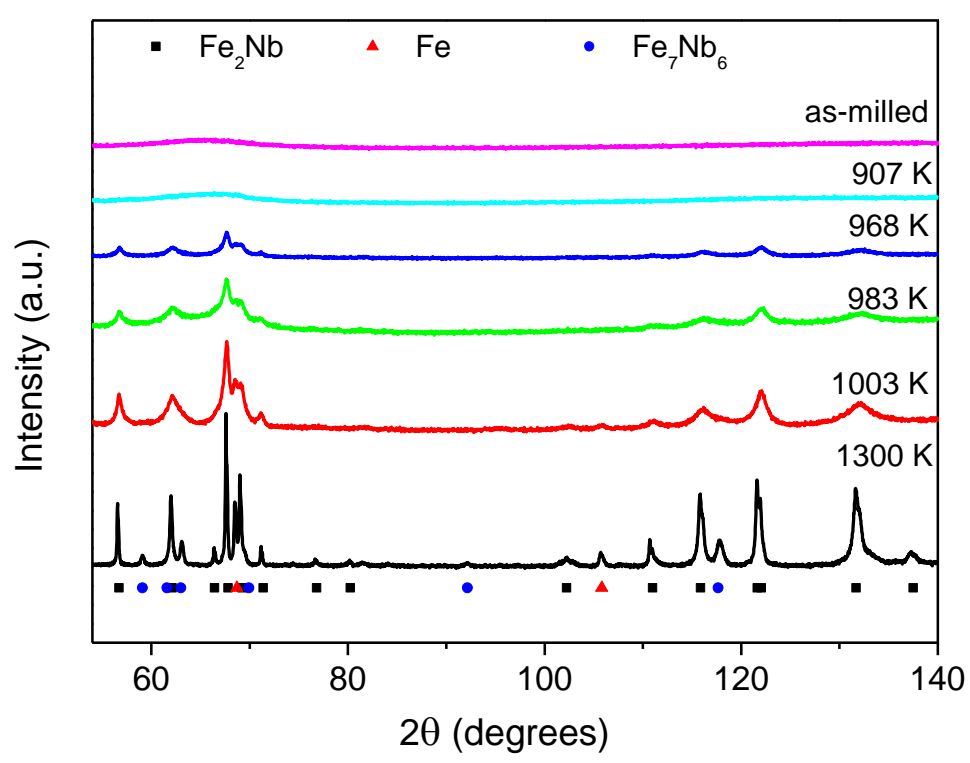

Figure 2. XRD patterns taken at room temperature of as-milled amorphous powders and of samples heated at $10 \mathrm{~K} / \mathrm{min}$ up to the indicated temperatures. These temperatures correspond to those indicated by arrows in Figure 1a.

Figure 3 shows the room temperature Mössbauer spectra of as-milled and heat treated samples up to the different indicated temperatures at $\beta=10 \mathrm{~K} / \mathrm{min}$. A quadrupolar distribution has been used to describe the paramagnetic contribution, assigned to the amorphous phase. The quadrupolar distribution is the unique contribution that exhibits 
the alloy heated up to $907 \mathrm{~K}$, in agreement with the XRD results, showing only an amorphous phase. Above this temperature, MS spectra show a decrease of the relative area of the quadrupolar distribution along with the appearance of a doublet, indicating the migration of $\mathrm{Fe}$ atoms to an ordered structure which corresponds to the $\mathrm{Fe}_{2} \mathrm{Nb}$ intermetallic detected by XRD. After heating up to $983 \mathrm{~K}$, besides the quadrupolar distribution and the doublet, a sextet appears with an hyperfine magnetic field of $32.84 \pm 0.09 \mathrm{~T}$ corresponding to the $\alpha$-Fe phase, detected also by XRD but after heating up to $1003 \mathrm{~K}$. In fact, MS is a more sensitive technique than XRD in order to detect small fractions of Fe-phases when paramagnetic and ferromagnetic phases coexist ${ }^{16}$. After heating up to $1300 \mathrm{~K}$, the alloy is totally crystalline, evidenced by the absence of any quadrupolar distribution. A new doublet was used to fit the spectrum showing the appearance of a new ordered phase, in agreement with the detection of $\mathrm{Fe}_{7} \mathrm{Nb}_{6}$ in the corresponding XRD patterns. The presence of doublets is frequently reported in the Mössbauer spectra of Fe-Nb alloys ${ }^{32-34}$.

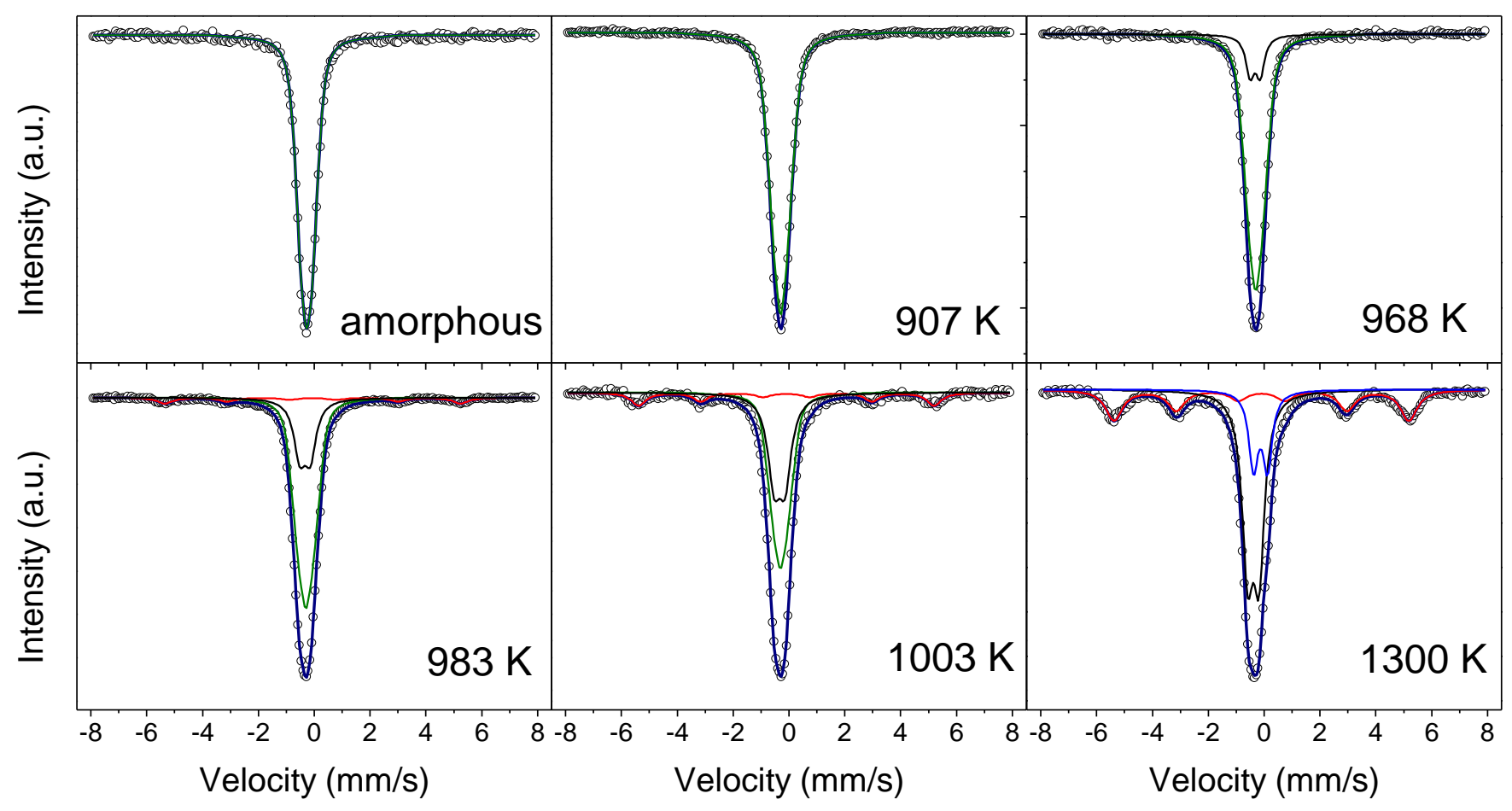


Figure 3. Experimental Mössbauer spectra taken at room temperature (symbols) and model fitting (lines) of as-milled and heat treated samples at $10 \mathrm{~K} / \mathrm{min}$ up to the indicated temperatures. These temperatures correspond to those indicated by arrows in Figure 1a. Green, black, red and blue subspectra correspond to $\mathrm{Fe}$ atoms in the amorphous, $\mathrm{Fe}_{2} \mathrm{Nb}, \alpha$ - $\mathrm{Fe}$ and $\mathrm{Fe}_{7} \mathrm{Nb}_{6}$ phases, respectively.

Figure $4 \mathrm{a}$ shows the evolution of the fraction areas of different contributions to Mössbauer spectra as a function of the final heating temperature at $\beta=10 \mathrm{~K} / \mathrm{min}$ (values at $300 \mathrm{~K}$ correspond to the as-milled sample with $100 \%$ amorphous phase). Doublet 1 (ascribed to $\mathrm{Fe}$ sites in $\mathrm{Fe}_{2} \mathrm{Nb}$ ) is the first contribution detected and its fraction shows a continuous increase up to $\sim 50 \%$ as the final heating temperature increases. The ferromagnetic site (ascribed to $\alpha$-Fe) is clearly detected after heating up to $983 \mathrm{~K}$. On the other hand, doublet 2 (ascribed to Fe sites in $\mathrm{Fe}_{7} \mathrm{Nb}_{6}$ ) is not detected until the sample is heated up to $1300 \mathrm{~K}$, when the area fraction of this contribution reaches $\sim 20 \%$. The different fraction areas of the samples are practically independent of the heating rate, as is shown in Fig. 4b. Only in the case of $\beta=5 \mathrm{~K} / \mathrm{min}$, the decrease of the doublet 1 fraction is compensated by an increase of the fraction of the ferromagnetic site and the doublet 2 .

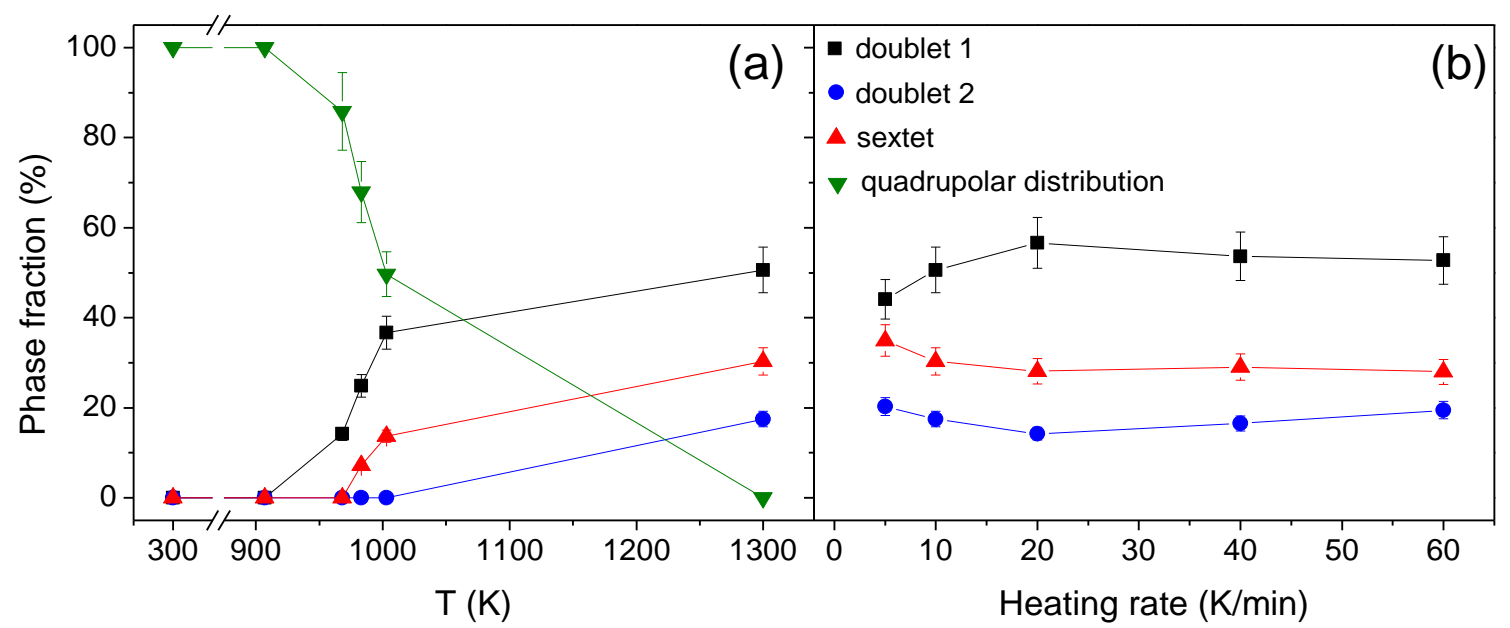

Figure 4. Evolution of the phase fraction obtained by MS as a function of a) the maximum heating temperature reached at $10 \mathrm{~K} / \mathrm{min}$ and b) the heating rate up to 1300 K. Lines are guides to the eye. 
The fitted hyperfine values for doublet 1 , attributed to the $\mathrm{Fe}_{2} \mathrm{Nb}$ crystalline phase, are a quadrupole splitting $Q=0.40 \pm 0.02 \mathrm{~mm} / \mathrm{s}$ and an isomer shift $\delta=-0.30 \pm 0.01 \mathrm{~mm} / \mathrm{s}$. Doublet 2, assigned to the $\mathrm{Fe}_{7} \mathrm{Nb}_{6}$ intermetallic, exhibits a $Q=0.45 \pm 0.07 \mathrm{~mm} / \mathrm{s}$ and $\delta=-$ $0.03 \pm 0.04 \mathrm{~mm} / \mathrm{s}$. These values and the average values found for the as-milled amorphous sample are shown in Table 1 and can be compared to those reported in the literature for samples prepared by different methods ${ }^{35-38}$. 
Table 1. Hyperfine parameters of as-milled amorphous alloy and of sample heated up to $1300 \mathrm{~K}$ along with those of other $\mathrm{FeNb}$ alloys from the literature. $\%$ is the relative contribution of the component, $\delta$ is the isomer shift relative to $\alpha$-Fe, $Q$ is the quadrupole splitting and $\mathrm{B}_{\mathrm{hf}}$ the hyperfine field magnetic field.

\begin{tabular}{|c|c|c|c|c|c|c|}
\hline Technique & Component & $\%$ & $\delta(\mathbf{m m} / \mathbf{s})$ & $Q(\mathrm{~mm} / \mathrm{s})$ & $B_{h f}(T)$ & Ref. \\
\hline $\begin{array}{l}\text { Mechanical } \\
\text { alloying }\end{array}$ & $\begin{array}{l}\text { Quadrupolar } \\
\text { distribution } \\
\text { (amorphous) }\end{array}$ & 100 & $-0.17 \pm 0.01$ & $0.32 \pm 0.01$ & - & $\begin{array}{l}\text { This } \\
\text { work }\end{array}$ \\
\hline \multirow[t]{3}{*}{$\begin{array}{l}\text { Mechanical } \\
\text { alloying } \quad+ \\
\text { heating treatment }\end{array}$} & $\begin{array}{l}\text { Doublet1 } \\
\left(\mathrm{Fe}_{2} \mathrm{Nb}\right)\end{array}$ & 47 & $-0.30 \pm 0.01$ & $0.40 \pm 0.02$ & - & \multirow[t]{3}{*}{$\begin{array}{l}\text { This } \\
\text { work }\end{array}$} \\
\hline & $\begin{array}{l}\text { Doublet } 2 \\
\left(\mathrm{Fe}_{7} \mathrm{Nb}_{6}\right)\end{array}$ & 23 & $-0.03 \pm 0.04$ & $0.45 \pm 0.07$ & - & \\
\hline & $\begin{array}{l}\text { Sextet } \\
(\alpha-\mathrm{Fe})\end{array}$ & 30 & $0.004 \pm 0.003$ & 0 & $32.84 \pm 0.09$ & \\
\hline \multirow{2}{*}{$\begin{array}{l}\text { Arc-melting }+ \\
\text { heating treatment }\end{array}$} & Doublet1 & - & -0.258 & 0.310 & - & \multirow[t]{2}{*}{35} \\
\hline & Doublet2 & - & -0.228 & 0.232 & - & \\
\hline \multirow{3}{*}{$\begin{array}{l}\text { Mechanical } \\
\text { alloying } \quad+ \\
\text { heating treatment }\end{array}$} & Doublet1 & 62 & $-0.19 \pm 0.01$ & $0.34 \pm 0.05$ & - & \multirow[t]{3}{*}{36} \\
\hline & Doublet2 & 18 & $0.02 \pm 0.05$ & $0.41 \pm 0.05$ & - & \\
\hline & Sextet & 20 & $0.00 \pm 0.05$ & $-0.04 \pm 0.05$ & $33.7 \pm 0.2$ & \\
\hline \multirow[t]{2}{*}{ Arc-melting } & Doublet1 & 15 & $-0.24 \pm 0.03$ & $0.37 \pm 0.04$ & - & \multirow[t]{2}{*}{37} \\
\hline & Sextet & 85 & $0.004 \pm 0.002$ & - & $32.63 \pm 0.02$ & \\
\hline \multirow{2}{*}{$\begin{array}{l}\text { Magnetron } \\
\text { sputtering }\end{array}$} & Doublet1 & 10 & $-0.3 \pm 0.1$ & $0.4 \pm 0.1$ & - & \multirow[t]{2}{*}{38} \\
\hline & Sextet & 65 & - & - & 33.1 & \\
\hline
\end{tabular}

Although values reported in the literature are similar, they are dispersed between those here assigned to the amorphous phase and those here assigned to the intermetallics. In the present study, the combination of the MS with XRD results of partially crystallized samples allowed us to unambiguously assign the hyperfine parameters to each of the phases detected. In fact, two doublets have been also detected by Raposo et al. ${ }^{35}$ for 
bulk alloys produced by arc-melting. They found $Q=0.31 \mathrm{~mm} / \mathrm{s}$ and $\delta=-0.258 \mathrm{~mm} / \mathrm{s}$ for $\mathrm{Fe}_{2} \mathrm{Nb}$ and $Q=0.232 \mathrm{~mm} / \mathrm{s}$ and $\delta=-0.228 \mathrm{~mm} / \mathrm{s}$ for $\mathrm{Fe}_{7} \mathrm{Nb}_{6}$. Although they reported clearly different values for $\mathrm{Fe}_{7} \mathrm{Nb}_{6}$ intermetallic, it is worth mentioning that this phase was not detected in their XRD patterns. In the work of Velez et al. ${ }^{36}$, the $\mathrm{Fe}_{7} \mathrm{Nb}_{6}$ phase was not detected from X-ray patterns but they reported two doublets to fit the Mössbauer spectra. However, they attributed the values of the second one $(Q=0.41 \pm 0.05 \mathrm{~mm} / \mathrm{s}$ and $\delta=0.02 \pm 0.01)$, which are close to those assigned in our study to $\mathrm{Fe}_{7} \mathrm{Nb}_{6}$, to "the contribution of the hcp amorphous grain boundaries and to the incoherent surface of these grains".

Figure 5 shows the temperature dependence of magnetization at 100 Oe during cooling samples previously heated up to the indicated temperatures. The as-milled amorphous sample heated up to $908 \mathrm{~K}$ undergoes magnetic transition from paramagnetic to ferromagnetic phase at $T_{C}=34 \mathrm{~K}$. After heating up to $968 \mathrm{~K}$ two magnetic transitions can be observed in agreement with the presence of amorphous and $\mathrm{Fe}_{2} \mathrm{Nb}$ phases detected from XRD patterns. Sample heated up to 973 K shows the same features. The first transition is still attributed to the $T_{C}$ of the amorphous phase, that changes from 34 to 84 $\mathrm{K}$. The second transition corresponds to the Curie temperature of the $\mathrm{Fe}_{2} \mathrm{Nb}$ phase, which changes from 177 to $189 \mathrm{~K}$ for the sample heated up to 968 and $973 \mathrm{~K}$, respectively. These changes in the $T_{C}$ can be understood if the compositional changes of the amorphous phase due to the formation of the intermetallic phase are considered. 


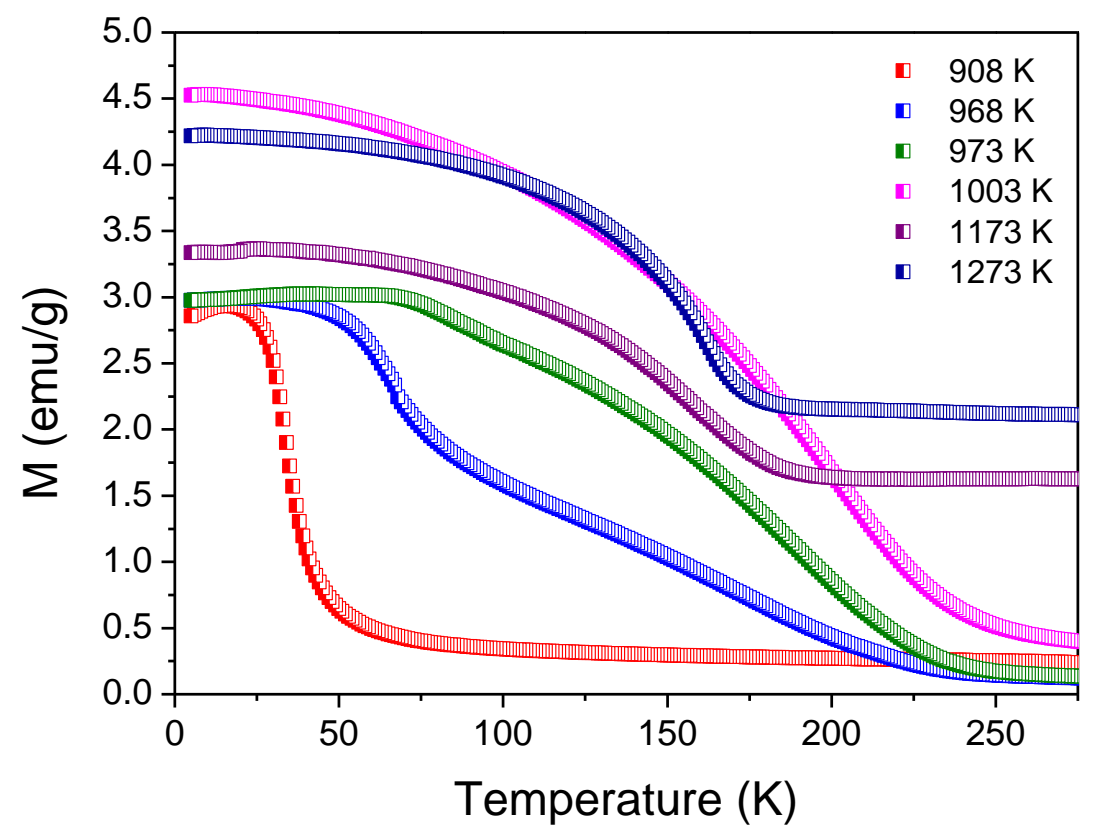

Figure 5. $\mathrm{M}(\mathrm{T})$ curves under a low magnetic field of 100 Oe for samples previously heated at $10 \mathrm{~K} / \mathrm{min}$ up to the indicated temperatures.

For samples heated up to $1003 \mathrm{~K}$, the contribution of the amorphous phase disappears and only a magnetic transition at $T_{C}=199 \mathrm{~K}$ can be observed, associated to the $\mathrm{Fe}_{2} \mathrm{Nb}$ intermetallic phase. Above this temperature, the magnetization does not go to zero above the $T_{C}$ of the $\mathrm{Fe}_{2} \mathrm{Nb}$ phase because of the developing of the $\alpha$-Fe phase, the amount of which increases as the temperature of the heating treatment increases, in good agreement with the XRD results. The final Curie temperature of the $\mathrm{Fe}_{2} \mathrm{Nb}$ phase is $162 \mathrm{~K}$. This decrease of $T_{C}$ corresponds to Fe depletion in the intermetallic phase due to the developing of the $\alpha$-Fe phase.

\subsection{Crystallization kinetics}

In order to obtain the local values of the Avrami exponents as a function of the transformed fraction, $n(X)$, DTA isothermal experiments were performed annealing the 
as-milled sample for 5 hours at $954 \mathrm{~K}(10 \mathrm{~K}$ below the onset temperature obtained for $\beta=10 \mathrm{~K} / \mathrm{min}$ ). Avrami exponent can be obtained from JMAK equation as:

$$
n=\frac{d(\ln [-\ln (1-X)])}{d\left(\ln \left(t-t_{0}\right)\right)}
$$

where $t_{0}$ is the induction time. A non-isothermal scan after the isothermal one did not show any exothermic peak, indicating that the transformation was completed during the isothermal treatment. This agrees with the detection of the three phases in XRD patterns of samples after the isothermal treatment (see figure 6a).

The transformed fraction $X$ has been approximated to the normalized transformed enthalpy, $X=\Delta H_{\text {iso }}(t) / \Delta H_{\text {total }}^{i s o}$, where $\Delta H_{\text {iso }}(t)$ is the enthalpy at a time $t$ and is obtained from integrating the isothermal DTA peak up to this time $t$, and $\Delta H_{\text {total }}^{\text {iso }}=40$ $\mathrm{J} / \mathrm{g}$ is the total enthalpy of the crystallization process. It is worth noticing that for very small and very high $X$ values, the effects of errors in baseline are more important.

Non-isothermal kinetics was also studied. In this case, a direct approach to nonisothermal processes of the JMAK theory has been applied ${ }^{28}$. This approach allows us to obtain the $n(X)$ values as:

$$
\frac{d(\ln [-\ln (1-X)])}{d\left(\ln \left[\frac{T-T_{0}}{\beta}\right]\right)}=n\left\{1+\frac{E_{a}}{R T}\left(1-\frac{T_{0}}{T}\right)\right\}
$$

where $E_{a}$ is the activation energy, $R$ is the ideal gas constant and $T_{0}=T_{p} / 2$, being $T_{p}$ the peak temperature, an effective onset temperature that minimizes the error of the used approximation $^{39}$. The transformed fraction has been approximated to the normalized transformed enthalpy, $X=\Delta H(T) / \Delta H_{\text {total }}^{\text {non-iso }}$, where $\Delta H(T)$ is the enthalpy developed up to temperature $T$ and $\Delta H_{\text {total }}^{\text {non-iso }}=59 \mathrm{~J} / \mathrm{g}$ is the enthalpy of the complete crystallization process. This larger enthalpy value with respect to that of isothermal 
treatment could be understood as a more developed crystallization process (grain growth and coalescence) in agreement with the XRD patterns shown in Figure 6a.
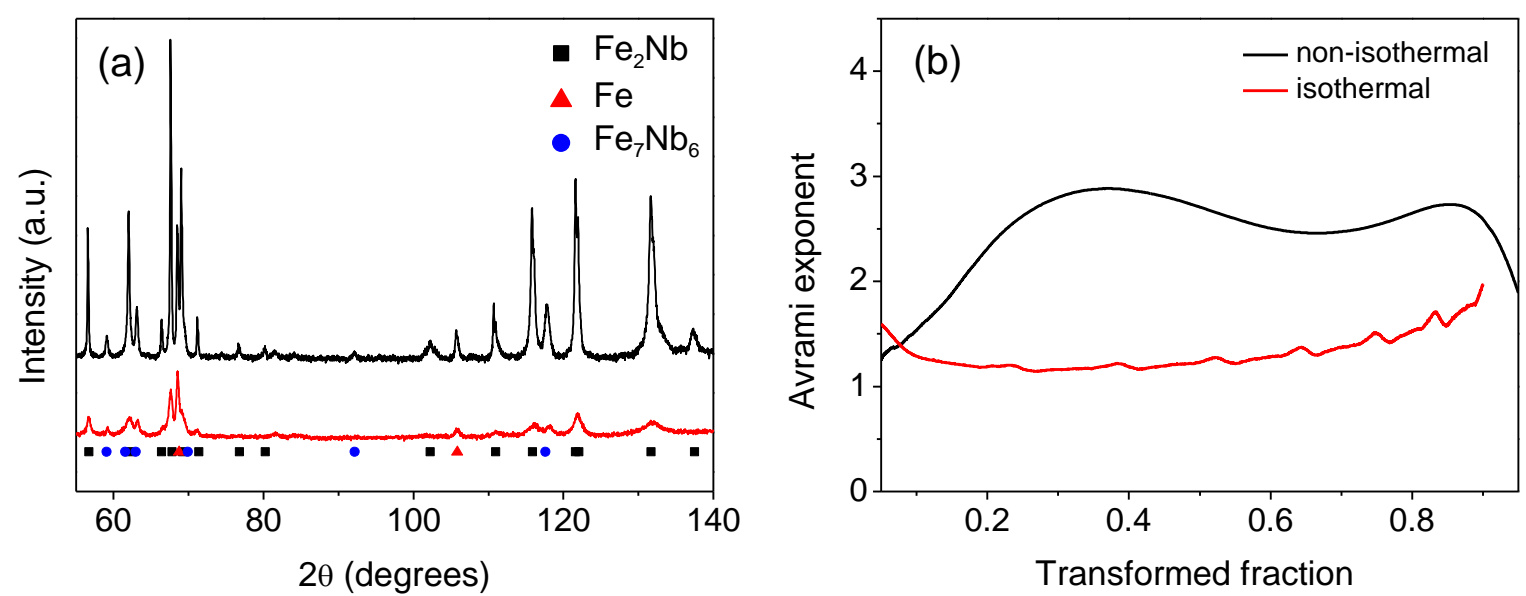

Figure 6. a) XRD patterns after non-isothermal treatment (heating at $10 \mathrm{~K} / \mathrm{min}$ up to the end of the first DTA exotherm; $\mathrm{T}=1300 \mathrm{~K}$ ) and isothermal one ( $5 \mathrm{~h}$ at $954 \mathrm{~K})$. b) Experimental local Avrami exponents as a function of transformed fraction of the crystallization process for $\mathrm{Fe}_{70} \mathrm{Nb}_{30}$ amorphous alloys heated at $\beta=10 \mathrm{~K} / \mathrm{min}$ and in isothermal regime $(\mathrm{T}=954 \mathrm{~K})$, respectively.

Figure $6 \mathrm{~b}$ shows the local Avrami exponent as a function of the transformed fraction $X$ calculated using Eq. 1 for isothermal treatment $\left(T_{i s o}=954 \mathrm{~K}\right)$ and Eq. 2 for nonisothermal one at $\beta=10 \mathrm{~K} / \mathrm{min}$ for the first exothermic peak. XRD and MS show that independent transformations simultaneously occur during the crystallization process (formation of the $\mathrm{Fe}_{2} \mathrm{Nb}, \alpha-\mathrm{Fe}$ and $\mathrm{Fe}_{7} \mathrm{Nb}_{6}$ crystalline phases). However, the first phase to appear is $\mathrm{Fe}_{2} \mathrm{Nb}$, which is also the main phase. Taking into account that after heating up to $1003 \mathrm{~K} \sim 90 \%$ of the enthalpy of the process is completed and besides $\mathrm{Fe}_{2} \mathrm{Nb}$ peaks, only traces of $\alpha$-Fe phase are observed, kinetic results should correspond mainly to the crystallization of $\mathrm{Fe}_{2} \mathrm{Nb}$ intermetallic.

The obtained values, $n_{i s o} \sim 1$, for the isothermal case are typical for nanocrystallization processes for which growth is severely impinged. In the case of the non-isothermal 
experiments, the Avrami exponent in the range $0.2<X<0.7$ is $n=2.65 \pm 0.16$. This can be interpreted as a constant nucleation rate and a three dimensional diffusion controlled growth (mainly formation of hexagonal $\mathrm{Fe}_{2} \mathrm{Nb}$ Laves phase). Therefore, the differences between isothermal and non-isothermal kinetic results could be ascribed to a stronger impingement in the growth of the $\mathrm{Fe}_{2} \mathrm{Nb}$ crystals in the isothermal regime. In fact, the isothermal growth process occurs at a much lower temperature than for non-isothermal treatments. This agrees with a much broader XRD diffraction maxima for isothermally annealed samples than for non-isothermal treated ones (Fig. 6a) indicating a clearly smaller crystallite size of the isothermally treated samples.

\section{Summary and conclusions}

Mechanical alloying allows us to obtain homogeneous $\mathrm{Nb}-30$ at.\% Fe amorphous alloy as a precursor system from which different iso- and non-isothermal treatments have been applied to develop crystalline stable phases. The products of the crystallization process have been studied by X-ray diffraction and Mössbauer spectroscopy as a function of both the final heating temperature and the heating rates. X-ray patterns clearly provide evidence of the formation of two intermetallics: $\mathrm{Fe}_{2} \mathrm{Nb}$ and $\mathrm{Fe}_{7} \mathrm{Nb}_{6}$, as well as bcc-Fe crystalline phase. Mössbauer spectra are consistent with the XRD results, showing the existence of three different kinds of local environments and allowing us to obtain the hyperfine parameters of the intermetallic phases. The decomposition of the paramagnetic contribution into two doublets indicates a migration of atoms from the amorphous phase to ordered structures, ascribed to intermetallic phases. The sequence in which they are detected from XRD allows us a clear assignment of the hyperfine parameters to each intermetallic phase. Temperature dependent magnetization curves 
show the evolution of the Curie temperatures of the amorphous and $\mathrm{Fe}_{2} \mathrm{Nb}$ phases during the crystallization, as well as the developing of the bcc-Fe crystalline phase.

JMAK theory has been used to describe the crystallization process in both isothermal and non-isothermal regimes. A stronger growth impingement in the isothermal regime can explain the lower Avrami exponent found with respect to those obtained for nonisothermal treatments.

\section{Acknowledgements}

This work was supported by AEI/FEDER-UE (Project MAT 2016-77265-R) and the PAI of the Regional Government of Andalucía. Support of the project APVV-15-0621 is also acknowledged. A.F. Manchón-Gordón acknowledges his contract to the VPPIUS of the University of Sevilla. 


\section{References}

$1 \quad$ N. Fujita, K. Ohmura, A. Yamamoto: Mater. Sci. Eng., A. 2003, vol. 351, pp. 272-281.

2 G.M. Sim, J.C. Ahn, S.C. Hong, K.J. Lee, K. S. Lee: Mater. Sci. Eng., A. 2005, vol. 396, pp. 159-165.

A. Malfliet, W. Van den Broek, F. Chassagne, J.D. Mithieux, B. Blanpain, P. Wollants: J. Alloy Comp. 2011, vol. 509, pp. 9583-9588. Y. Kang, W.M. Mao, Y.J. Chen, J. Jing, M. Cheng: Mater. Sci. Eng., A. 2016, vol. 677, pp. 453-464.

M.E. McHenry, M.A. Willard, D.E. Laughlin: Prog. Mater. Sci. 1999, vol. 44, pp. 291-433. L.E. Zamora, G.A.P. Alcazar, J.A. Tabares, J.D. Betancur, F.R. Sives, J. Jaen, J.M. Greneche, J.F. Marco, J.M. Gonzalez: J. Phys. D: Appl. Phys. 2008, vol. 41, p. 155010. G. Herzer: Scr. Metall. Mater. 1995, vol. 33, pp. 1741-1756. S. Voss, M. Palm, F. Stein, D. Raabe: J. Phase Equilib. Diffus. 2011, vol. 32, pp. 97-104. K.W. Li, X.B. Wang, S.M. Li, W.X. Wang, S.P. Chen, D.Q. Gong, J.L. Cui: High. Temp. Mater. Processes (Berlin, Ger.) 2015, vol. 34, pp. 479-485.

10 C.G. Schon, J.A.S. Tenorio: Intermetallics 1996, vol. 4, pp. 211-216.

11 H.J. Goldschmidt: Research (London) 1957, vol. 10, pp. 289-291.

12 A. Takeuchi, A. Inoue: Mater. Trans., JIM 2000, vol. 41, pp. 1372-1378.

13 E.P. Abrahamson, S.L. Lopata: Trans. Metall. Soc. AIME 1966, vol. 236, pp. 76-87.

14 J.J. Ipus, J.S. Blázquez, V. Franco, A. Conde, L.F. Kiss: Intermetallics 2010, vol. 18, pp. 565-568.

15 J.S. Blázquez, J.J. Ipus, S. Lozano-Perez, A. Conde: JOM 2013, vol. 65, pp. 870-882.

16 A.F. Manchón-Gordón, J.J. Ipus, J.S.; Blázquez, C.F. Conde, A. Conde: J. Non-Cryst. Solids 2018, vol. 494, pp. 78-85.

17 J. Balogh, L. Bujdoso, D. Kaptas, T. Kemeny, I. Vincze, S. Szabo, D.L. Beke: Phys. Rev. B 2000, vol. 61, pp. 4109-4116.

18 J.S. Blázquez, J.J. Ipus, V. Franco, C.F. Conde, A. Conde: J. Alloy Comp. 2014, vol. 610, pp. 92-99.

19 W.A. Johnson, R.F. Mehl: Tech. Publ. - Am. Inst. Min. Metall. Eng. 1939, 135, 416-442.

20 M. Avrami: J. Chem. Phys. 1941, vol. 9, pp. 177-184.

21 A.N. Kolmogorov, Bull. Russ. Acad. Sci. 1937, vol. 1, pp. 355-359.

22 P. Bruna, D. Crespo, R. Gonzalez-Cinca, E. Pineda: J. Appl. Phys. 2006, vol. 100, p. 054907.

23 J.S. Blázquez, M. Millán, C.F. Conde, A. Conde: J. Alloy Comp. 2010, vol. 505, pp. 91-95.

24 T. Ozawa, Polymer 1971, vol. 12, pp. 150-158.

25 K. Nakamura, T. Watanabe, K. Katayama: J. Appl. Polym. Sci. 1972, vol. 16, pp. 10771091.

26 K. Nakamura, T. Watanabe, T. Amano: J. Appl. Polym. Sci. 1974, vol. 18, pp. 615-623.

27 M.J. Starink, A.M. Zahra: Thermochim. Acta 1997, vol. 298, pp. 179-189.

28 J.S. Blázquez, C.F. Conde, A. Conde: Acta Mater. 2005, vol. 53, pp. 2305-2311.

29 J. Torrens-Serra, P. Bruna, S. Roth, J. Rodriguez-Viejo, M.T. Clavaguera-Mora: J. Alloy Comp. 2010, vol. 496, pp. 202-207.

30 R.A. Brand, J. Lauer, D.M. Herlach: J. Phys. D: Appl. Phys. 1983, vol. 13, pp. 675-683.

31 H.E. Kissinger: Anal. Chem. 1957, vol. 29, pp. 1702-1706.

32 M.S. El-Eskandarany, A.A. Bahgat, N.S. Gomaa, N.A. Eissa: J. Alloy Comp. 1999, vol. 290, pp. 181-190.

33 E. Jartych, D. Oleszak, J.K. Zurawicz: Hyperfine Interact. 2001, vol. 136, pp.25-33.

34 G.Y. Velez, G.A. Perez Alcazar, L.E. Zamora: J. Magn. Magn. Mater. 2014, vol. 354, pp. 333-335.

35 M.T. Raposo, J.D. Ardisson, A.I.C. Persiano, R.A. Mansur: Hyperfine Interact. 1994, vol. 83 , pp. 235-238. 
36 G.Y. Velez, G.A. Perez Alcazar, L.E. Zamora, J.A. Tabares: J. Supercond. Novel Magn. 2014, vol. 27, pp. 1279-1283.

37 A. Blachowski, K. Ruebenbauer, J. Zukrowski: Phys. Status Solidi B 2005, vol. 242, pp. 3201-3208.

38 M.J.M. Pires, W.A.A. Macedo, L.P. Cavalcanti, A.M.G. Carvalho, J. Phys. Chem. Solids 2015, vol. 86, pp. 36-41.

39 J.S. Blázquez, J.M. Borrego, C.F. Conde, A. Conde, S. Lozano-Perez: J. Alloy Comp. 2012, vol. 544, pp. 73-81. 